\title{
Influence of the Magnetite Nanoparticles on Dielectric Properties of Nanocomposites on the Basis of Linear Polyethylene of Low Density
}

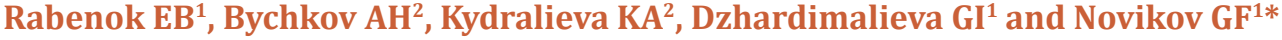 \\ ${ }^{1}$ Institute of problems of chemical physics of the Russian Academy of Sciences, Russian Federation \\ ${ }^{2}$ Moscow aviation institute, national research university, Russian Federation
}

Submission: April 26, 2018; Published: May 23, 2018

*Corresponding author: Novikov GF, Institute of problems of chemical physics of the Russian Academy of Sciences, Chernogolovka, Russian Federation, Tel/Fax: +7 49652 21842; Email: gfnovikov@gmail.com

\begin{abstract}
The nanocomposite of magnetite/linear low-density polyethylene has been synthesized. Influence of magnetite nanoparticles in concentration $1-20 \mathrm{wt} \%$ on dielectric properties and conductivity of nanocomposites in the range of frequencies $10^{-2}-10^{5} \mathrm{~Hz}$ and temperatures from 113 to $383 \mathrm{~K}$ have been studied. Inclusion of particles of magnetite in polyethylene slightly changed melting temperature. But at the same time an imaginary part of complex dielectric permittivity increased sharply (on two orders of size) and enthalpy of fusion decreased by $25 \mathrm{~J} / \mathrm{g}$.

Keywords: Linear low-density polyethylene; Magnetite; Dielectric properties; Electrical conductance
\end{abstract}

\section{Introduction}

Development of polymeric composition materials is one of the priority directions of development of modern technologies and the equipment. A unique combination of valuable properties of polymeric matrices such as film formation, mechanical strength, chemo-and corrosion resistance, on the one hand, and functional properties of nanodimensional fillers, -with another hand, allows to consider such materials as perspective for use in aerospace technology, instrument making, microelectronics, medicine and other hi-tech fields of the industry [1].

The main engine of development of consumption of the composition materials $(\mathrm{CM})$ is resource-saving: weight reduction, increase in productivity, cost cutting. Among composition materials of different function special attention is paid to materials on the basis of polyolefins. They attract with technological effectiveness, small specific weight and low cost. Development highly effective thermo flexible CM, containing different functional nanofillers and processed into products by means of high-performance technologies, is a relevant scientific and technical task. For receiving metal-polymeric nanocomposite materials various approaches are developed. Among them methods of dispergating of metallic nanoparticles or their formation directly in a polymeric matrix and also the synthesis of nanocomposites consisting in simultaneous formation of the high-dispersed particles and the stabilizing polymeric matrix were widely adopted.
Different types of polyethylene (PE), for example, were used as a polymeric matrix for $\mathrm{TiO}_{2}$ and $\mathrm{TiO}_{2} / \mathrm{Ag}$ nanoparticles [2,3], $\mathrm{Cu}$ [4]. For example, copper nanoparticles with different contents from 1 to $3 \mathrm{wt} \%$ were synthesized by in situ thermal decomposition of the precursor in the melt of PE. The diffraction patterns of the nanocomposites obtained have peaks of both LLDPE ( $\left.21.65 ; 23.95 ; 30.10 ; 36.3 ; 40.75 ; 42.95^{\circ}\right)$, and copper nanoparticles ( $43.40 ; 50.45$ and $74.15^{\circ}$ ). Copper nanoparticles, produced in the PE melt have dimensions of $20-30 \mathrm{~nm}$ with a narrower size distribution. The received hybrid materials showed improvement of mechanical, thermal and barrier properties. The modified MgO nanoparticles (3wt\%) in a matrix of linear polyethylene of low density (LLDPE) had significant effect on DC conductivity of polymer, reducing it honor by 100 times [5] that is explained that the surface of nanoparticles can actively connect polar molecules, ions, charges of particles though, in general, the nature of such influence remains until the end of not clear.

The purpose of the real work is studying of influence of magnetite nanoparticles on dielectric properties of nano composites on the basis of linear polyethylene of low density.

\section{Experimental Part}

\section{Receiving magnetite}

The solution of $\mathrm{FeCl}_{3} * 6 \mathrm{H}_{2} \mathrm{O}$ and $\mathrm{FeCl}_{2} * 4 \mathrm{H}_{2} \mathrm{O}$ crystalline hydrates in water was prepared at molar ratio 2:1. The 
concentrated $\mathrm{NH}_{4} \mathrm{OH}$ was added to solution at $40{ }^{\circ} \mathrm{C}$ at intensive stirring within $10-15 \mathrm{~min}$. Reaction mixture was kept by $30 \mathrm{~min}$. The formed precipitate of black color was washed out in water before neutral reaction, separated by means of a static magnet or centrifuging within $15 \mathrm{~min}$., washed out in addition with ethyl alcohol and stored in dry benzene.

\section{Receiving nanocomposites}

The LLDPE $-\mathrm{Fe}_{3} \mathrm{O}_{4}$ nanocomposites with filler content of 0.5-20wt. \% were received by mixing of LLDPE and filler with use of an extruder of HAAKE of Minilab of the Rheomex CTW5 type with synchronous rotation of two conic screws in the argon atmosphere. Extruding temperature was $150{ }^{\circ} \mathrm{C}$, screw speed was $60 \mathrm{RPM}$, and duration of material loading was $20 \mathrm{RPM}$. Time of hashing was of 10-20min. Film samples of nanocomposites received by method of hot pressing with use of the manual electro warmed hydraulic press.

\section{X-ray phase analysis}

The analysis was carried out on the x-ray powder diffractometer"DRON-UM-2". The size of particles was calculated on the basis of line broadening in a range on Sherrer's equation: $d=K \lambda /(\beta \cos \theta)$, where d-the average size of domains (crystallites); K-the dimensionless coefficient of a form of particles (Sherrer constant a) making $\sim 0.9$; $\beta$-reflex width (on a half of the maximum intensity); $\lambda$-the wavelength of $x$-ray radiation; $\theta$-the angle of diffraction.

\section{Electronic and microscopic researches}

Electronic and microscopic researches were conducted by means of the scanning auto emission electron microscope of "Zeiss SUPRA 25". X-ray spectral energy dispersive analysis of samples was carried out on the INCA Energy prefix to a scanning electron microscope of "Zeiss SUPRA 25" at an acceleration voltage of 9kW. IR spectra are registered on tablets with $\mathrm{KBr}$ on the Specord-M80 spectrophotometer of Carl Zeiss (Germany) equipped with the Soft spectra program. DSC analysis of composites carried out with using the Mettler DSC 30 device at a speed of heating of 10 hails/min.

\section{Dielectric measurements}

Dielectric measurements were taken in frequency band $f=10^{-2}-10^{5} \mathrm{~Hz}$ and temperatures from 113 to $383{ }^{\circ} \mathrm{C}$ with using "A broadband dielectric spectrometer" of Novo control GMBH. Sample temperature during measurements was controlled about accuracy $0.5{ }^{\circ} \mathrm{C}$. The measuring cell consisted of two electrodes from stainless steel. Diameter of electrodes is $20 \mathrm{~mm}$. Tension between electrodes did not exceed $1 \mathrm{~V}$.

\section{Results and Discussion}

\section{Synthesis, morphology and microstructure of $\mathrm{Fe}_{3} \mathrm{O}_{4} /$ LLDPE nanocomposites}

The magnetite nanoparticles were obtained by chemical reaction of aqueous solutions of iron (II) and (III) chlorides in the presence of alkali in argon. Data of the element analysis (found/calculated, \%) are: Fe - 71, 89/72, 36; O - 27, 82/27, 64; IR, , $\mathrm{CM}^{-1}:$ 580, 640 (Fe-O), 1580-1481, 935-830 (OH).

The structure, morphology and microstructure of the received nanocomposition materials are investigated by the X-ray methods and electronic microscopy. Filler nanoparticles during dispersion are rather evenly distributed in volume of a matrix, both particles of the initial sizes, and their conglomerates are observed (Figure 1), what is confirmed by also widened peaks on the x-ray diffractograms corresponding to a nanofiller phase.

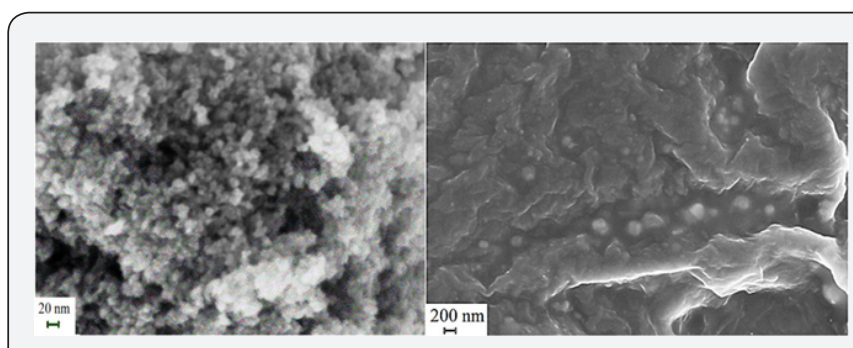

Figure 1: Electronic and microscopic images of nanoparticles of magnetite (a) and $10 \mathrm{Fe}_{3} \mathrm{O}_{4}$ PE nanocomposites (b)

Table 1: Temperature, melting heat and degree of crystallinity of nanocomposites of $\mathrm{Fe}_{3} \mathrm{O}_{4} /$ LLDPE.

\begin{tabular}{|c|c|c|c|}
\hline Sample & $\mathbf{F e}_{3} \mathbf{O}_{4} / \mathbf{L L D P E}$ & & \\
\hline & $\mathbf{t m l},{ }^{\circ} \mathbf{C}$ & $\Delta \mathbf{H m l}, \mathbf{J} / \mathbf{g}$ & $\chi \mathbf{~}, \%$ \\
\hline $0.5 \mathrm{Fe}_{3} \mathrm{O}_{4} \mathrm{PE}$ & 124.7 & 119 & 42 \\
\hline $1 \mathrm{Fe}_{3} \mathrm{O}_{4} \mathrm{PE}$ & 124.7 & 132 & 46 \\
\hline $3 \mathrm{Fe}_{3} \mathrm{O}_{4} \mathrm{PE}$ & 124.6 & 109 & 40 \\
\hline $5 \mathrm{Fe}_{3} \mathrm{O}_{4} \mathrm{PE}$ & 124.3 & 107 & 38 \\
\hline $10 \mathrm{Fe}_{3} \mathrm{O}_{4} \mathrm{PE}$ & 124.7 & 105 & 37 \\
\hline $20 \mathrm{Fe}_{3} \mathrm{O}_{4} \mathrm{PE}$ & 124.8 & 95 & 33 \\
\hline
\end{tabular}

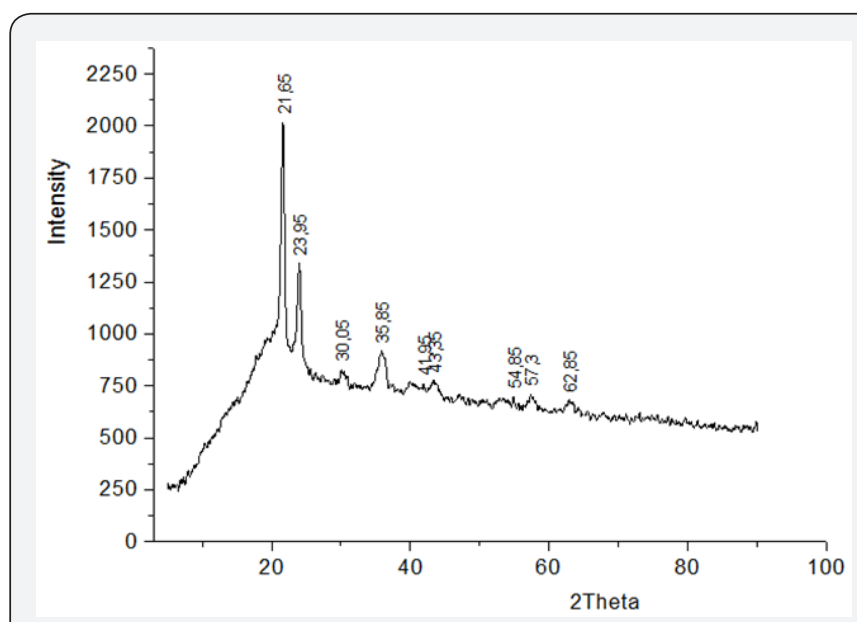

Figure 2: XRD- diffractogram of the $10 \mathrm{Fe}_{3} \mathrm{O}_{4} \mathrm{PE}$ nanocomposite.

Systematic reduction of an enthalpy of melting $\Delta \mathrm{H}$ is established at increase in maintenance of nanoparticles of 
magnetite in a polymeric matrix of LLDPE (Table 1). The similar filler content dependence is characteristic for the degree of crystallinity of nanocomposites calculated by a formula $\chi=N_{\downarrow} /$ $N_{100}{ }^{*} 100 \%$ where $\mathrm{N}_{\mathrm{v}^{*}}$ - the heat which is marked out during the melting of a sample, $\mathrm{H}_{100}$ - the heat which is marked out when melting $100 \%$ of crystal polymer for LLDPE of $\mathrm{N}_{100}=285 \mathrm{~J} / \mathrm{g}$ [6] (Figure 2).

\section{Dielectric properties of the $\mathrm{Fe}_{3} \mathrm{O}_{4} /$ LLDPE nanocomposites}

The dependences of real parts of complex electrical conductance of $\sigma^{*}=j e_{0} w e^{*}=\sigma^{\prime}+j \sigma^{\prime \prime}$ on frequency in composite films on the basis of polyethylene with different concentration of $\mathrm{Fe}_{3} \mathrm{O}_{4}$ measured at a temperature of $373 \mathrm{~K}$ are shown in Figure 3.

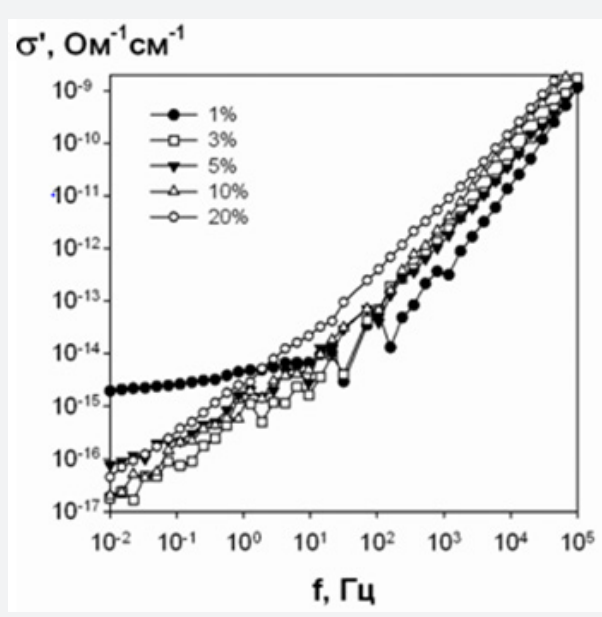

Figure 3: Dependence of $\sigma^{\prime}(f)$ in composite films on the basis of polyethylene with different concentration of $\mathrm{Fe}_{3} \mathrm{O}_{4} . \mathrm{T}=373 \mathrm{~K}$.

It can be seen that the plot $\log \left(\sigma^{\prime}\right)=\varphi(\log (f))$ for films of the containing 1 wt. $\%$ of $\mathrm{Fe}_{3} \mathrm{O}_{4}$ has two components. In highfrequency band conductivity depends on frequency. In low frequency band conductivity does not depend on frequency. It is natural to carry the expressed plateau in the low frequencies band which extends to the area of high frequencies with growth of temperature to transport of free charges [7] - dc-conductivity.

Transition from area of the plateau to a high-frequency part of dependence of ac-conductivity, $\sigma_{a c}(f)$, corresponds to change of the mechanism of electrical conductance. Area of the plateau in the left part of dependence $\log \left(\sigma^{\prime}\right)=\varphi(\log (f))$ reflects the movement of charges on long distances. In the right part of increases with increase in frequency, and the movement of charges is limited to space of their potential holes. Let's notice that in both cases the derivative for time of the total electric dipolar moment is responsible for emergence of current in an external circuit. It can be seen from the Figure 3 that the change of the mechanism of electrical conductance is observed at lower frequencies $\mathrm{f}^{*}$ at increase in concentration of the embedded $\mathrm{Fe}_{3} \mathrm{O}_{4}$.

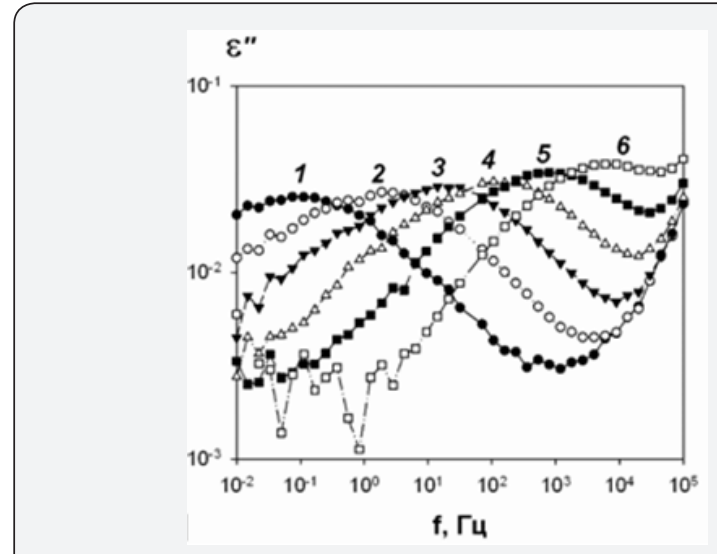

Figure 4: The $\varepsilon^{\prime \prime}(f)$ dependencies of composite films on the basis of polyethylene with the maintenance of $10 \mathrm{wt} . \%$ of $\mathrm{Fe}_{3} \mathrm{O}_{4}$ for different temperatures. 1 - 143; 2 - 183; 3 - 223; 4 - 263; 5 303; 6-343K

On (Figure 4) the dependence of imaginary ${ }^{\varepsilon "}(f)$ part, $\varepsilon^{\prime \prime}$, of complex dielectric permittivity $\varepsilon^{*=\varepsilon^{\prime}-j \varepsilon^{\prime \prime}}$ on frequency in composite films with the maintenance of $10 \mathrm{wt} . \%$ of $\mathrm{Fe}_{3} \mathrm{O}_{4}$ for different temperatures. It can be seen from the drawing that two picas are observed on the dependence $\varepsilon^{\prime \prime}(f)$ : low-frequency peaks $\left(P_{1}-f_{\max }<10^{4} H\right)$ and high-frequency one $\left(\dot{P}_{2}-f_{\max }>10^{4} \mathrm{~Hz}\right)$. The peak P1 is displaced towards higher frequencies with growth of temperature. While the peak $\mathrm{P}_{2}$ (which appeared on the edge of the frequency range) of the device does not depend on measurement temperature.

The dependence of imaginary $\varepsilon^{\prime \prime}$ of complex dielectric permittivity on frequency in composite films with different concentration of $\mathrm{Fe}_{3} \mathrm{O}_{4}$ measured at a temperature of $223 \mathrm{~K}$ is provided in Figure 5. It is seen from the drawing that not only increase in amplitude of the peak $\mathrm{P}_{1}$, but also shift on frequency is observed at increase in concentration of the embedded $\mathrm{Fe}_{3} \mathrm{O}_{4}$.

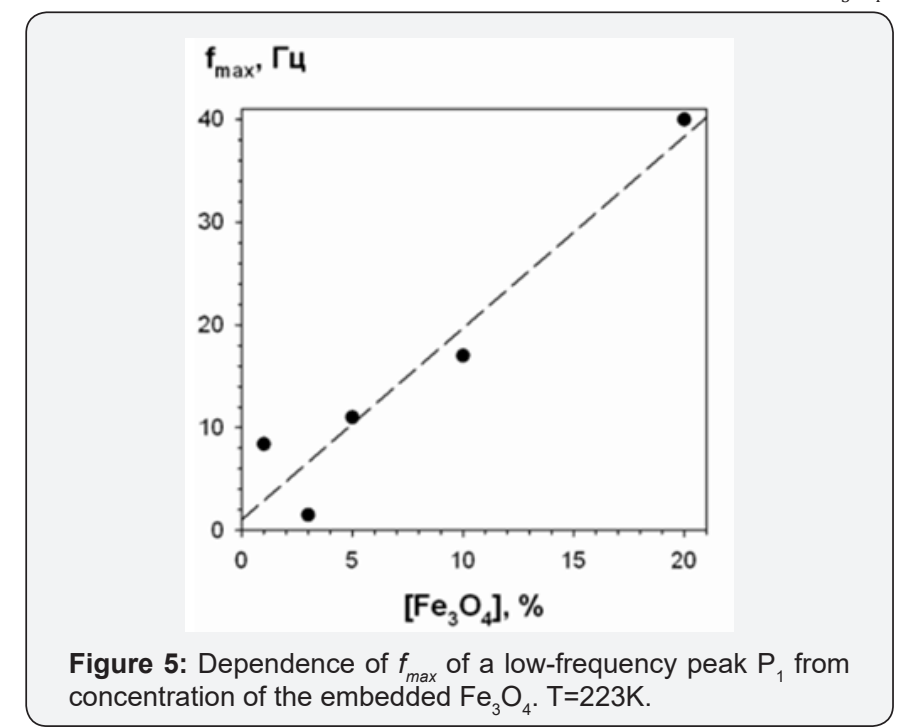

The dependence of a low-frequency peak $\mathrm{P}_{1}$ from concentration of the embedded $\mathrm{Fe}_{3} \mathrm{O}_{4}$ at temperature of $223 \mathrm{~K}$ is shown in Figure 6. 


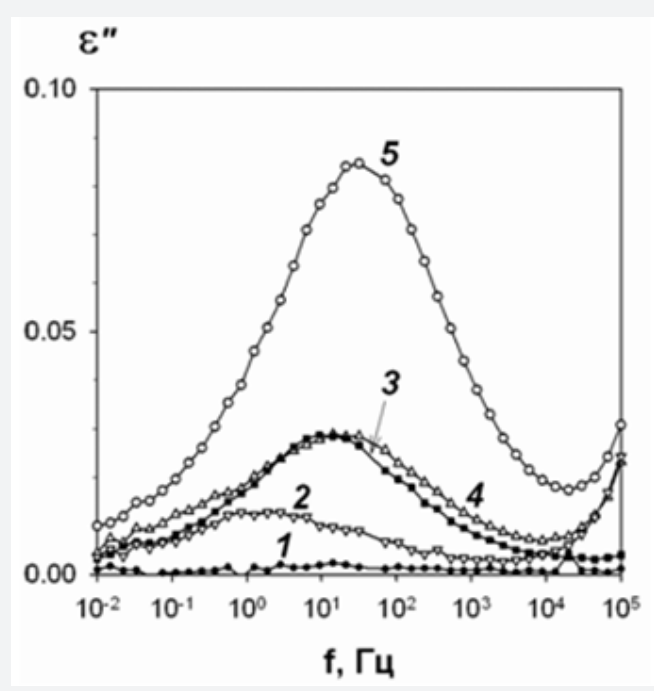

Figure 6: Dependence of "from frequency in composite films with different concentration of $\mathrm{Fe}_{3} \mathrm{O}_{4} .1-1 ; 2-3 ; 3-5 ; 4-10$; 5- 20wt. \%.T=223K.

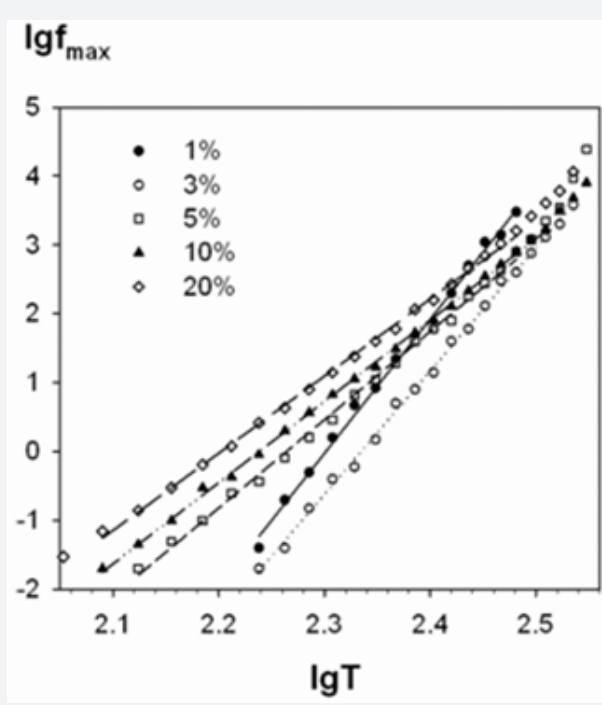

Figure 7: Dependence of provision of $f_{\max } P_{1}$ from temperature in composite films with different concentration of $\mathrm{Fe}_{3} \mathrm{O}_{4}$ additive in logarithmic coordinates.
The dependences of $f_{\max }$ of the peak $\mathrm{P}_{1}$ on measurement temperature for different structure of a composite are shown in (Figure 7) in logarithmic coordinates. The provided results indicate an essential contribution of percolation to properties of a composite. However, data (Figure 7) demonstrate unusually strong power characteristic of provision of frequency of maximum $\mathrm{P}_{1}$ on temperature that demands the additional analysis.

We are going to carry out the detailed theoretic analysis of influence of nanoparticles of magnetite on dielectric properties of nanocomposites on the basis of linear polyethylene of low density in the following unrolled publication.

\section{Acknowledgement}

The work was performed within the frameworks of Projects No. 01201055328 and No.0089-2014-0036).

\section{References}

1. Pomogaylo AD, Rosenberg A, Uflyand IE (2000) Nanoparticles of metals in polymers. Moscow: Chemistry pp. 672.

2. Wang Z, Wang X, Zhang Z (2009) Nucleating activation and spherical crystals morphology of LLDPE/LDPE/TiO2 nanocomposites prepared by non-isothermal crystallization. Journal of Dispersion Science and Technology 30(8): 1231-1236.

3. Polat S, Fenercioglu H, Güçlü M (2018) Effects of metal nanoparticles on the physical and migration properties of low density polyethylene films. Journal of Food Engineering 229: 32-42.

4. Pomogaylo DA, Fetisov GP, Koksharov SA, Pomogaylo SI, Kydralieva KA (2015) The nanocomposites on the basis of polyethylene films decorated by copper: receiving, structure and anticorrosive properties. Technology of metals 9: 36-41.

5. Nilsson F, Karlsson M, Pallon L, Giacinti M, Richard T, et al. (2017) Influence of water uptake on the electrical DC conductivity of insulating LDPE/MgOnanocomposites. Composites Science and Technology 152: 11-19.

6. Yu I, Averko-Antonovich RT, Bikmullin K (2002) Research techniques of structure and properties of polymers. pp. 604.

7. Novikov GF, Rabenok EV, Estrin YaI, Olkhov Yu A, Badamshina ER (2014) Influence of small concentration of carbon nanotubes on conductivity of polyurethane elastomer. Journal of physical chemistry 88(10): 1605-1609.

\section{Your next submission with Juniper Publishers will reach you the below assets}

- Quality Editorial service

- Swift Peer Review

- Reprints availability

- E-prints Service

- Manuscript Podcast for convenient understanding

- Global attainment for your research

- Manuscript accessibility in different formats

( Pdf, E-pub, Full Text, Audio)

- Unceasing customer service

Track the below URL for one-step submission https://juniperpublishers.com/online-submission.php 